\title{
PRÁTICAS DE LETRAMENTOS VERNACULARES COM LITERATURA: interações desenvolvidas por acadêmicos de letras em ambientes virtuais ${ }^{1}$
}

\author{
Jacqueline Leire ROEPKE ${ }^{2}$ \\ Caique Fernando FISTAROL ${ }^{3}$ \\ Adriana FISCHER ${ }^{4}$
}

\begin{abstract}
Resumo
Práticas de letramentos vernaculares são efetivadas, na vida pessoal, por iniciativa e interesses próprios. Nessas práticas, a internet tem transformado modos de acesso e de produção. Partindo dessas considerações, busca-se compreender práticas de letramentos vernaculares com literatura desenvolvidas por acadêmicos de um curso de Letras em ambientes virtuais. O presente trabalho possui como marco teórico principal os Novos Estudos dos Letramentos. Trata-se de pesquisa dotipo etnográfica, realizada durante o segundo semestre de 2016, tendo como sujeitos três acadêmicos. Os dados foram gerados por observação participante, questionário e entrevista. As análises permitem constatar que acadêmicos se dedicam às práticas vernaculares, ainda que estas não sejam reconhecidas por instituições educacionais. Acadêmicos de Letras aglutinam práticas vernaculares às práticas institucionalizadas, sinalizando, assim, que a linha de divisa não é rigidamente demarcada. Nesse sentido, instituições educacionais podem refletir sobre modos de tornar as práticas de letramentos, para que façam mais sentido aos estudantes.
\end{abstract}

Palavras-chave: Letramentos Vernaculares. Práticas de Letramentos. Ambientes Virtuais. Recursos Digitais.

\footnotetext{
${ }^{1}$ Esta pesquisa contou com o apoio da Fundação de Amparo à Pesquisa e Inovação do Estado de Santa Catarina - FAPESC.

${ }^{2}$ Mestre em Educação. Especialista em Educação Infantil e Anos Iniciais, em Psicopedagogia, em Educação a Distância: Gestão e Tutoria e em Psicologia Organizacional e do Trabalho. Graduada em Psicologia - FURB Universidade Regional de Blumenau.

E-mail: jacleire@gmail.com

${ }^{3}$ Mestre em Educação pela Universidade Regional de Blumenau. Especialista em Metodologia do Ensino de Língua Portuguesa e Estrangeira, Mídias da Educação pela e Coordenação Pedagógica. Graduado em Letras.

E-mail: cfersf@gmail.com

${ }^{4}$ Doutora e mestre em Linguística. Graduada em Letras. FURB Universidade Regional de Blumenau.

E-mail: afischerpirotta@gmail.com
} 


\title{
VERNACULAR LITERACY PRACTICES WITH LITERATURE: interactions developed by students of languages in virtual environments
}

Jacqueline Leire ROEPKE

Caique Fernando FISTAROL

Adriana FISCHER

\begin{abstract}
Vernacular literacy practices are brought in to effect in one's personal life through the irown initiative and interest. In such practices, the internet has been transforming the way so facces sand production. From the se considerations, weseek tounder stand vernacular literacy practices with literature developed by students majoring in Languages in virtual environments. The present work has as theoretical framework in the New Literacy Studies. This is a qualitative research, withaneth no graphic perspective, conducted during the second semester of 2016, with thre estudents. Data were generated through participant observation, questionnaire and interview. The analyses help determine that these students are dedicated to vernacular practices, although these are not recognized by the educational institutions. Majoring students in Languages bind vernacular practices to institutionalized practices, thussign alingth at the boundary line is not rigidly outlined. In this sense, educational institutions can reflecton ways to transforme literacy practices that are developed within, so that they make more sense to the students.
\end{abstract}

Keywords: Vernacular Literacies. Literacy Practices. Virtual Environments. Digital Resources. 


\title{
Introdução
}

\begin{abstract}
“Um livro é um jardim, um pomar, um armazém, um grupo de pessoas, uma companhia, aliás, um conselheiro, uma multidão de consultores".
\end{abstract}

Henry Beecher

Há aproximadamente duzentos anos, o escritor estadunidense Beecher já atribuía ao livro o caráter social. Afinal, um jardim é composto por um conjunto de flores e plantas, um pomar expressa o coletivo de frutas, um armazém só pode ser um armazém pela quantidade de produtos que estão em seu interior. Uma única unidade não faz daquela estrutura física um armazém. E quando Beecher menciona pessoas, as coloca depois da palavra grupo, e, em poucas letras depois, escreve o vocábulo "multidão".

Bakhtin (2004) também se debruçou sobre esta característica que não está presente apenas nos livros, mas em toda as suas formas de linguagens: o dialogismo, que diz respeito ao diálogo que se estabelece entre os interlocutores, bem como ao diálogo com outros textos (da situação da enunciação). Dessa forma, a significação é construída dialógica e historicamente na e pela mediação com e pelo outro social. O dialogismo explicita o princípio essencial da linguagem, e é imprescindível para a construção do sentido do discurso. Sob este ângulo, o discurso jamais é individual, porquanto se constrói entre, pelo menos, dois interlocutores que, por sua vez, são seres sociais, históricos e interpelados pela(s) ideologia(s).

Se essas premissas já eram válidas há duzentos ou cem anos, quando expressas por Beecher ou Bakhtin, numa época em que as práticas de letramentos com escrita geralmente eram manuscritas ou impressas, quanto mais com o advento dos recursos digitais em ambientes virtuais, quando as produções escritas passam por notáveis transformações. Nessa linha de pensamento, a internet tem possibilitado que pessoas que nunca se viram pessoalmente face a face estejam escrevendo um texto juntas, ao mesmo tempo por meio de (fóruns, e-mails, salas de bate-papo, redes sociais, blogs, aplicativos de comunicação, plataforma de vídeos, etc). Essa prática social, além de facilitar o acesso das produções escritas ao longo da história, tem permitido que se reflita sobre/com elas e se escreva a partir dessas produções. Assim, o dialogismo se faz ainda mais presente, dinâmico e abrangente.

Levando em conta as mudanças que vêm se desenrolando na sociedade no século XXI, propiciadas pelos recursos digitais, parte-se do pressuposto que o processo de constituição do sujeito-leitor na atualidade, recebe influências destas interações em ambientes virtuais, bem como o processo de formação de professores. Com apoio nessas considerações, o objetivo do artigo é compreender práticas de letramentos vernaculares com literatura desenvolvidas por acadêmicos do curso de Letras em ambientes virtuais. 
Para tanto, esse estudo é permeado pela seguinte pergunta de pesquisa: como são desenvolvidas práticas de letramentos vernaculares com literatura por acadêmicos de um curso de Letras em ambientes virtuais?

Foi realizada uma pesquisa de cunho qualitativo, de perspectiva etnográfica, envolvendo três acadêmicos do curso de Letras. Os dados foram analisados à luz da perspectiva sociocultural dos estudos dos letramentos (STREET, 2014), por conseguinte, concebe os letramentos enquanto práticas sociais e culturais que envolvem o uso de texto; englobando comportamentos com leitura, escrita e fala.

Para atender ao objetivo proposto, este artigo está subdivido em três seções: desenvolvimento teórico, percursos metodológicos e análises em torno de práticas de letramentos vernaculares em ambientes virtuais.

\section{Desenvolvimento Teórico}

"O livro traz a vantagem de a gente poder estar só e ao mesmo tempo acompanhado".

Mário Quintana

O pensamento do poeta brasileiro Quintana corrobora com a noção de companhia, de pluralidade, de coletividade e de relacionamento que um leitor estabelece com um autor, apresentada na seção anterior sob a ótica de Beecher. É com apoio nessa abordagem relacional que se esta seção teórica se apresenta ao leitor.

Na perspectiva de Street (2013), as práticas de leitura e escrita que as pessoas engendram não são efetuadas com neutralidade, ou com motivações exclusivamente técnicas, que são unívocas, tampouco, que permanecem inalteráveis. Por isso, Street (2013), de certa forma, desprendeu os letramentos da aquisição de habilidades de leitura e escrita, e de práticas de ensino de letramentos, dando foco aos usos e respectivos sentidos.

As pessoas aprendem a ler e a escrever de modos singulares, personalizados, movidos por interesses distintos, e conforme vão se inserindo no mundo das letras, passam a fazer inúmeros usos da leitura e da escrita. Assim, a perspectiva de Street (2013) é mais atenta ao caráter social, cultural, e pessoal das atividades que envolvem ler e escrever econsiderafatores ideológicos, de identidade, de relações de poder, de sentidos, ainda, os usos sociais que os constituem.

Os letramentos são construídos por sujeitos na e pela interação com seus grupos, no cotidiano. Alguns fatores influenciam os letramentos, como lugar, instituições, finalidades, período histórico, circunstâncias econômicas e relações de poder (STREET, 2014). As relações de poder influenciam também as práticas com letramentos.

Por práticas de letramentos compreende-seo conjunto de eventos e padrões, em que os textos assumem papel central, associando-os com sua natureza social e cultural. Trata-se das formas peculiares de pensar e efetivar a leitura em contextos situados. As práticas de letramentos se referem tanto aos usos quanto aos significados culturais acerca da leitura e 
da escrita, inclusive das concepções que os sujeitos têm dos processos de ler e escrever, enquanto estão engendrando um evento de letramento (STREET, 2003). Práticas de letramentos até podem exibir determinados padrões de atividade, porém elas não se restringem a esses padrões. Diversamente, elas são amplas, no sentido de serem complexas, atreladas a aspectos das esferas sociais e culturais.

Em vista dessas características, práticas de letramentos vernaculares comumente são construídas informalmente, uma vez que pertencem ao âmbito pessoal, privado, livre e espontâneo. Costumam representar uma escolha pessoal do usuário das tecnologiasdigitais e são geridas por ele. São atreladas à construção da identidade pessoal enquanto leitor e escritor, mesmo que geralmente sejam desprestigiadas socialmente pelas instâncias dominantes. Práticas de letramentos vernacularessempre existiram, antes mesmo da invenção dos recursos digitais em ambientes virtuais. O que difere, nos dias atuais, são os suportes em que elas se processam, assim como os contextos e recursos empregados, cada vez mais sofisticados (CASSANY, 2015).

As práticas vernaculares foram caracterizadas por Street (2013) como práticas extraescolares, práticas que resistem, em muitas circunstâncias, indicadas como letramentos marginalizados, em virtude de serem efetivadas à margem das práticas determinadas pelas esferas dominantes, que são institucionalizadas.

Portanto, esse artigo embasa-se na visão sociocultural acerca das práticas de letramentos, queconsidera aspectos contextuais, culturais, ideológicos e pessoais. A leitura, por exemplo, é compreendida na sua relação com outras práticas sociais. Nessa direção, as análisesrecaem sobre o discurso de três universitários do curso de Letras, acerca de suas próprias interações em ambientes virtuais em torno do que eles entendem por literatura. Esses discursos são considerados situadamente, e a expressão de suas opiniões entendidas como artefatos sociais de caráter político. Afinal, ser leitor de literatura é assumir um papel social, vinculado com questões de identidade (CASSANY, 2016). Leitura e escrita são atividades humanas específicas, situadas histórica e socialmente na vida de cada pessoa e da comunidade, de acordo com seus interesses e necessidades (ALIAGAS; CASTELLÀ; CASSANY, 2009).

A esse respeito, Cassany e Hernández (2012) trazem dados deum estudo de caso realizado com uma jovem que não foi aprovada em um curso de Letras, apesar de desenvolver variadas práticas de letramentos no cotidiano e que eram elogiadas na internet, tais como: participações em fóruns, compartilhamento de suas escritas acerca de poemas, música e quadrinhos. Ela lê e escreve em três idiomas, além de conhecer e tirar proveito de vários programas e recursos linguísticos. Os textos são capítulos de histórias, poemas ou comentários de leitores e autores, e versam sobre temas variados: histórias assustadoras, fantásticas, românticas, eróticas, de aventuras, contos e poemas (CASSANY; HERNÁNDEZ, 2012). 
Aliagas, Castellà e Cassany (2009) também realizam um estudo de caso com um jovem, que apresenta desinteresse pela leitura acadêmica, e que, inclusive, desiste dos estudos. Os autores buscam levantar pontos de vista e crenças acerca de práticas de leitura dominantes e vernaculares desenvolvidas pelo jovem. No que se refere às práticas de escrita no domínio privado, ele gostava de exprimir seus sentimentos em diários, poesias ou cartas. Era uma maneira de sublimar livremente suas emoções, refletir e encontrar acalento sem preocupar-se tanto com as regras canônicas (ALIAGAS; CASTELLÀ; CASSANY, 2009). Esses autores apontam que o jovem foi grandemente influenciado pela imagem de si mesmo como aluno rebelde. Ele tinha consciência de que ler era uma atividade importante, mas entrava em conflito consigo mesmo, pois seus gostos e modos de leitura divergiam daqueles que eram requeridos no contexto escolar. Assim, ele foi convencido de que era uma pessoa que não apreciava a leitura, por mais que quisesse apreciá-la. O jovem construiu dois sentidos diferentes para a leitura: um para a leitura da vida e outro para a leitura da escola. Na vida, assumia o papel de leitor, sem se dar conta de que a leitura é perpassada por aspectos sociais, funcionais e práticos, ao passo que a leitura acadêmica lhe parecia um exercício extremamente sofisticado e intelectualizado.

Desse modo, o jovem do estudo de caso apresentado por Aliagas, Casstellà e Cassany (2009) possuía um conflito de representação leitora, e que esta situação não diz respeito apenas a ele. Pouco se conhece sobre jovens que têm menor apreço por leituras do contexto escolar do que em espaços não institucionalizados. Por isso, um dos objetivos da pesquisa de Aliagas, Castellà e Cassany (2009) foi romper com a visão que naturaliza os estudos sobre a formação do leitor, colocando seu foco sobre habilidades psicocognitivas. Para tanto, destacaram a utilidade que pode ter a etnografia, em oferecer um olhar mais amplo para o fenômeno de desinteresse na leitura. Ademais, ao compreender tais resistências à leitura, pode fornecer pistas sobre como o professor pode agir diante desse contexto. No âmbito de um discurso deficitário, o jovem em questão lê pouco. Entretanto, para esses autores, se for levada em conta a teoria social da leitura, constata-se que embora ele não tenha atingido a expectativa do sistema acadêmico, aprendeu sobre o mundo da leitura em situações vernaculares e efetivava práticas de letramentos diversificadas fora do contexto escolar.

Sob o mesmo enfoque dos dados anteriormente mencionados, Cassany (2010) defende que práticas vernaculares podem configurar formas originais de traduzir preocupações literárias, que pode ser útil a educadores ao planejarem suas intervenções educativas. Assim, esses autores tecem reflexões sobre as maneiras de ler e escrever na internet, em atividades desvinculadas da esfera escolar. Examinam diferenças entre as práticas acadêmicas e vernaculares, refletindo sobre as relações entre elas e a educação.

Dadas essas compreensões acerca de práticas de letramentos vernaculares, na sequência, descrevem-se os procedimentos metodológicos. A seção posterior, então, 
abordará práticas de letramento vernaculares em ambientes virtuais, que dizem respeito à escrita e à leitura no contexto da vida particular dos três sujeitos da pesquisa.

\section{Percursos metodológicos}

"Pensava que nós seguíamos caminhos já feitos, mas parece que não os há. O nosso ir faz o caminho.”

Clive Staples Lewis

Os percursos metodológicos de uma pesquisa qualitativa não podem ser totalmente traçados previamente pelo pesquisador, pois, ao interagir com os sujeitos de pesquisa, há inúmeras variáveis que não se podem antever, e há novos rumos que se descortinam, desdenhando o itinerário imaginado pelo pesquisador. Ainda que Lewis, possivelmente, não estivesse fazendo uma alusão à metodologia de pesquisa científica, ao escrever suas palavras, ela se aplica a esse contexto. Afinal, o caminho da pesquisa qualitativa é um caminho que vai sendo feito pouco a pouco pelo caminhar do pesquisador.

Por consequência, para responderà pergunta de pesquisa, optou-se por realizar uma investigação qualitativa (BOGDAN; BIKLEN, 1994). Tencionou-se olhar para as práticas de letramentos vernaculares dos acadêmicos de Letras sob a ótica etnográfica (FRITZEN, 2012), portanto, buscando entender o que eles fazem, como fazem e por quê, sem julgamento de valor à qualidade ou adequação de suas leituras e produções escritas (CASSANY, 2010).

Como instrumentos de geração de dados, inicialmente foi realizada a observação participante no decorrer da disciplina de Literatura Brasileira em 2016, na sexta fase do curso de Letras presencial de uma universidade do interior de SC. Durante as aulas, alguns acadêmicos se sobressaíam em comentários sobre as práticas de letramentos que desenvolviam por interesse próprio, fora do contexto universitário. Posteriormente, um questionário, que foi aplicado em novembro de 2016, contribuiu para a definição dos sujeitos que seriam ouvidos por meio de entrevista semiestruturada. O critério de seleção abrangeu a demonstração de maior afinidade com obras literárias. De início, foram selecionadas duas acadêmicas, posteriormente, mais umacadêmico veio a ser selecionado, conforme especificado mais adiante. Os três sujeitos aceitaram participar da pesquisa e foram entrevistados, individualmente, em maio de 2017. Cada entrevista foi gravada, e depois foi transcrita para a concretização das análises. Eles escolheram os seguintes pseudônimos: Sofia, Emily e Dante.

Sofia tem 21 anos, e ao longo das observações das aulas de Literatura, era a acadêmica que mais participativa nos diálogos com o professor. Geralmente, antes de adentrar nos conteúdos específicos da disciplina, o professor fazia sugestões informais de leituras e mencionava livros que estavam sendo lançados. Frequentemente, Sofia demonstrava estar atenta aos lançamentos e, em adição, listava outros títulos novos. Muitas 
vezes, quando o professor citava algum livro clássico, ou popular, ela relatava ter lido e verbalizava suas impressões. Em uma das aulas, ele perguntou a ela onde ela buscava tais informações, e ela explicou que fazia parte de grupos com este interesse na internet.

Ademais, Sofia foi a acadêmica da sala que assinalou mais alternativas na questão do questionário acerca da avaliação dela sobre a relação com a literatura:

Tenho elevado interesse por literatura; leio livros de literatura por espontânea vontade (interesse próprio); prefiro literatura brasileira; prefiro literatura inglesa; aprecio literatura espanhola. Para ela, literatura é uma forma de exprimir nossos sentimentos, descrever nossa realidade.

Emily tem 20 anos e, durante as observações das aulas de Literatura, nota-se que ela costumava ler, pois trazia livros para a sala de aula, nas interações verbais com o professor fazia menção aos livros que já tinha lido e expressava suas opiniões acerca das obras. Nas conversas informais com os colegas, também comentava sobre livros que estava lendo.

No questionário, Emily assinalou as seguintes alternativas, no que concerne à avaliação de sua relação com a literatura: tenho interesse por literatura; leio livros de literatura por espontânea vontade (interesse próprio); aprecio literatura norte americana. O conceito de literatura que ela escreveu no questionário foi: para mim, literatura é uma forma de expressão artística, de sentimentos, por meio das palavras.

Dante tinha 21 anos, na ocasião da geração dos dados, geralmente permanecia em silêncio durante as aulas. Costumava ter livros sobre sua carteira, raramente comentava sobre algo que havia lido. Ao final de uma aula, o professor comentou, com uma das autoras deste artigo, que Dante era um acadêmico que visivelmente lia muito, mas que nunca foi muito participativo nas aulas dele.

Seis meses depois que o questionário havia sido aplicado, as duas acadêmicas foram contatadas para o agendamento das entrevistas. Outras duas pessoas da sala estavam selecionadas para fazer parte da pesquisa, no entanto, quando convidadas, via o Messenger do Facebook, para marcar a entrevista, ambas indicaram Dante, já que a pesquisa envolvia práticas de letramentos com literatura em ambientes virtuais. Elas ressaltaram que ele era o acadêmico da sala mais envolvido com práticas vernaculares com literatura na internet, e enfatizaram o interesse dele por mangás e animes.

No questionário, Dante apontou as alternativas que seguem, para avaliar sua relação com a literatura: tenho elevado interesse por literatura; leio livros de literatura por espontânea vontade (interesse próprio); aprecio literatura japonesa. O conceito de literatura que ele redigiu no questionário foi: literatura para mim é o passado, o presente e o futuro de uma nação. É um meio de passar adiante e manter viva uma cultura. É um meio de aprendizado, entretenimento e comunicação.

Assim que foi contatado para conversar sobre a pesquisa, Dante se mostrou receptivo e ao tomar conhecimento de que se tratava de uma investigação sobre literatura em ambientes virtuais, manifestou muita empolgação. A entrevista com Dante foi a mais longa, excedendo duas horas de duração. Foi algo inesperado, considerando que era tão 
calado em sala de aula. O comportamento de Dante em sala de aula, como acadêmico, não dava indícios de que ele tivesse tantos interesses em literatura.

Pode-se observar que pessoas que desenvolviam práticas de letramentos vernaculares similares às de Dante foram sujeitos de pesquisa de algumas investigações feitas pelo espanhol Daniel Cassany, que em parceria com outros autores, trouxe à tona resultados de uma série de pesquisas sobre práticas de letramentos vernaculares em ambientes virtuais, que foram apresentadas na seção antecedente. Isso posto, parte-se para a próxima seção, que enfoca a apresentação e a análise de práticas de leitura e escrita que os acadêmicos de Letras realizam com recursos digitais em ambientes virtuais.

\section{Práticas de letramentos vernaculares em ambientes virtuais}

"Literatura não estraga fora da geladeira nem fora da universidade". Fabrício Carpinejar

Para compreender os usos que fazem das tecnologias digitais, relacionados com a literatura, interpretou-se, inicialmente, quais são as tecnologias utilizadas pelos sujeitos neste trabalho - acadêmicos de Letras. Na entrevista, Sofia afirmou ser usuária das seguintes redes sociais: Facebook, Instagram, WhatsApp, e YouTube. O Facebook foi apontado por ela como a rede mais utilizada para a leitura vinculada com a literatura. Em relação à Emily, esta admitiu utilizar as seguintes redes sociais: Facebook, Twitter, Instagram, Snapchat, WhatsApp, YouTube, Skoob e Pinterest. Asseverou ter encontrado esses canais em suas buscas pessoais, muitas vezes nos motores de busca da internet. Dante, por sua vez, listou as seguintes redes sociais: Facebook, YouTube, Tambler, Twitter, WhatsApp e Messenger do Facebook, e comentou as finalidades com que utiliza cada uma delas. Mencionou que outrora fora usuário do Skype, Orkut e MSN.

O desenvolvimento de tecnologias digitais, diversificaram as práticas de letramento, possibilitando, por exemplo, a realização de práticas de cooperação on-line (ZHANG; CASSANY, 2016). Muitos usuários têm utilizado as redes sociais para efetivar práticas de letramentos com literatura, como Facebook, Twitter, Tuenti. Também tem sido frequente o uso de programas de mensagens como o WhatsApp, Line e Telegram, para criação de grupos, em que os usuários trocam informações sobre interesses em literatura. Essas ferramentas permitem a criação de um perfil virtual, por meio do qual o usuário interage com os demais, compartilhando determinados conteúdos (CASSANY, 2016).

Por exemplo, ao final da entrevista, quando o diálogo versava sobre compartilhamento de postagens sobre literatura, Sofia afirmou: “mas Facebook é pra compartilhar o que a gente gosta, né?" Com esta frase, Sofia quis justificar os compartilhamentos nesta rede social, reforçando que o Facebook serve para disseminar as coisas prediletas dos seus usuários. Essa fala corrobora que práticas de letramentos 
vernaculares denotam atividades arbitrárias, fortemente ligadas ao interesse pessoal (CASSANY, 2010).

Na sequência, apresentam-se como os sujeitos utilizam as tecnologias digitais, com vistas às práticas de letramentos com literatura.

Sofia rememorou um momento em que a navegação no Facebook lhe remeteu a algo que havia aprendido recentemente na universidade:

Um dia eu até vi um meme sobre a cena do Shakespeare, e como eu estava estudando Shakespeare eu vi e eu entendi e eu achei muito bacana.

Esta fala expressa que ela se divertiu ao ver a postagem no Facebook, sobre um gracejo feito acerca de um trecho escrito por Shakespeare. Apesar de conceber a literatura como expressão de sentimentos e descrição da realidade, Sofia deu indícios de que por meio da associação entre literatura e ambientes virtuais, ela se deleita, ou seja, sente prazer quando encontra algo que faça sentido para ela:

Ah eu compartilho, às vezes eu comento, ou pego alguma coisa pra usar com os meus alunos. [...] no ano passado quando eu dava português, daí eu pegava às vezes o que aparecia no Facebook, e usava com eles daí, né?

Dessa forma, Sofia compartilha algumas postagens concernentes à literatura, de modo que seus alunos, que são seus amigos na rede social, possam acessar o conteúdo compartilhado. Além disso, ela se utiliza de postagens para comentar em sala de aula, ou mesmo como inspiração nas aulas que ministra. Assim, apesar de Cassany e Hernández (2012) desmembrarem práticas de letramentos escolarizadas das práticas de letramentos da vida, diferenciando-as, Sofia parece fazer algumas junções entre elas. Assim como o meme do Shakespeare, visto num momento de lazer, reforçou algo que ela estudou na universidade, ela utiliza postagens que visualiza em seu Facebook, para incrementar as aulas que conduz na escola.

Ainda que as perguntas da entrevista tenham focado aspectos pessoais e privados das práticas com literatura, compreendeu-se, na fala de Sofia, que sua vida pessoal está fortemente arraigada a sua formação e atuação docente, uma vez que relaciona seus usos com a internet e a literatura, nos momentos de lazer, com suas práticas em sala de aula. Sofia expressa sua aprovação e admiração pelos espaços virtuais destacando outros usos que realiza na escola, já que os considera como ferramentas potenciais de aprendizagem:

Ah, eu acho muito bacana. Principalmente os vídeos. [...] Às vezes a gente pode mostrar pra um aluno, pode mostrar pra ele sobre algum autor, e daí o aluno pode se interessar e querer ler e facilita bastante o acesso, né... É fácil de acessar, fácil de ver, fácil de aprender... Bem utilizável, principalmente na escola, assim, com os alunos.

Quando Sofia faz a repetição da palavra “fácil”, está fazendo menção à linguagem utilizada na rede social, que já é de uso corrente para os seus alunos, que são adolescentes, conforme ela enfatiza em outras partes da entrevista. Vale lembrar que se trata da escrita ideofonemática, que é casual, coloquial e dá maior liberdade para que os jovens que 
marquem sua identidade, de modo que revelem sua personalidade e sejam reconhecidos pelos outros on-line (CASSANY, 2010; 2015).

Além disso, vale lembrar que grande parte dos seus alunos possuem as habilidades necessárias para interagirem e agirem pela linguagem mediada pela tecnologia, pois já utilizam o Facebook há certo tempo.

Eu acredito que os recursos digitais facilitem o acesso à literatura. Eu acho que pode aumentar, a gente pode ter outros meios de aumentar de fazer os alunos se interessarem mais pela literatura. Eu vejo dessa forma.

Tanto nas observações, quanto no questionário e na entrevista ficou evidente que Sofia gosta de literatura, e ela atribui tanta importância à literatura, que citou várias estratégias que visam estimular o interesse pela literatura em seus alunos. Supostamente, Sofia vê um potencial nos recursos digitais para atrair a atenção dos estudantes, pois, na escola, comumente, práticas de letramentos com literatura têm sido abordadas de forma desvinculada das práticas sociais dos estudantes, ligadas tão somente a normas e procedimentos vigentes na escola, com uma abordagem mais mecanizada, voltada ao conhecimento teórico (CASSANY; HERNÁNDEZ, 2012). Já os ambientes virtuais podem aumentar as chances de que a literatura faça sentido para os estudantes, pois, na internet, os estudantes têm empregado estratégias pessoais em prol do aumento de seu conhecimento, dos assuntos que os agradam espontaneamente. Ademais, existem inúmeras possibilidades de associar sons e imagens, de modo mais atrativo, e poder selecionar o que se quer ler, ao invés de ter de ler apenas o que a escola delimita.

No que se refere às redes sociais vinculadas à literatura, Emily relatou fazer os seguintes usos:

\begin{abstract}
Ah! No Instagram, eu curto uma página de literatura infantil, que eu acho muito interessante. Eles disponibilizam livros para as crianças, então, é um material bem legal que eu costumo dar uma olhada assim... No Facebook, eu curto páginas de literatura, então, de vez em quando, tem um poema, tem alguma parte que eu paro e leio... Ah! eu uso também muito o Pinterest,que é um site de figuras e eu gosto muito de tirinhas e poemas também, então, eu sempre procuro lá. Porque lá eu encontro já bonitinho, numa foto, bem arrumadinhas as tirinhas e eu gosto muito de quadrinhos.
\end{abstract}

A internet demanda novos modos de leitura e de escrita, com características peculiares, que acarretam transformações no processo de ler e escrever. Em alguns momentos, Emily pode procurar por poemas ou tirinhas específicos nas fontes digitais que mais aprecia, mas, por vezes, esses textos vão se sobrepondo velozmente. Lê-se um poema, e dois segundos depois se está rindo de uma tirinha. No poema encontra-se um link, que direciona o internauta para outro poema e assim, de forma dinâmica, gêneros diversos e híbridos vão se intercalando a cada clique do mouse. Emily também demonstra navegar nestes espaços tanto para fins educacionais, quanto para deleite. 
Emily citou três gêneros discursivos distintos: livros, poemas e tirinhas, que ela acessa por meio da internet. Como aponta Cassany (2010), práticas de letramentos vernaculares com poesia e prosa aparecem em blogs, fóruns, fotologs ou troca de textos. Incluem criações, reproduções originais ou parciais ou totais das letras de canções de grupos de música ou autores da história da literatura em sua língua original ou traduzidos. Poemas são lidos e discutidos por meio de diferentes linguagens e registros. Muitas vezes a poesia é utilizada para a criação de sentido na vida durante a juventude. Os jovens se amparam em poesias para felicitar pessoas com as quais se importam em datas importantes ou para fazer dedicatórias. Frequentemente, utilizam fragmentos de poesia como legendas de fotos ou nos comentários feitos em redes sociais (CASSANY, 2010).

Emily ainda citou que na maioria das vezes procurava resenhas de livros, antes de adquirir um livro. Ora ela as busca em formato de texto, ora em formato de vídeo. Esporadicamente, vai em busca de resenhas, depois de ter lido o livro:

Às vezes, para ter uma interpretação que eu não tinha antes do texto. Às vezes, eu assisto à resenha, depois ou antes, daí eu já tenho uma base pra minha leitura. Ou me faz pensar depois que eu já li, faz pensar de uma forma diferente. Então ajuda na minha interpretação.

Emily, expressa que utiliza conteúdos virtuais para produzir sentidos acerca de livros que tenha lido, ou que venha começar a ler. Na internet, os jovens podem ler sobre seus gêneros discursivos prediletos, com procedimentos que eles mesmos escolhem, e nas fontes que apresentam o capital linguístico que os interessa. Inclusive, podem encontrar possibilidades de construir sentidos sobre o que leem, atrelados à sua identidade social, bem como, a estabelecer vínculos com outros internautas (CASSANY; HERNÁNDEZ, 2012).

Até as fanfics fazendo coisa sobre literatura eu acho bem válido. Porque eu na graduação consulto outras pessoas pra ter uma opinião diferente, pra refletir mais sobre as coisas. Então acho que principalmente pra quem tá no ensino médio e tem aulas de português é uma coisa muito boa, que eles conseguem consultar. Às vezes, eles até têm um pouco de preguiça de ler. Se eles pelo menos veem uma resenha, se eles têm contato com isso, eles têm uma ideia do que que é a história e podem ter um contato maior com a literatura e talvez até se interessem mesmo em ler o livro. Então, eu acho que essas coisas são bem legais.

De acordo com Cassany (2010), as fanficssão produções escritas de ficção-mania, ou seja, equivalem à recriação do universo de uma obra popular para o deleite pessoal. Tratase de escrever novas aventuras tomando elementos de obras originais. Aceita mistura de vários meios de comunicação (literatura, televisão, cinema, história em quadrinhos, jogos) e vários gêneros (ficção científica, literatura fantástica, sagas). Tem atraído maior interesse de fãs de obras populares, como Crepúsculo e O Senhor dos Anéis, Harry Potter. Os integrantes das fanfics tomam alguns cuidados quanto à censura (idade dos leitores), e seguem regras no que se refere ao plágio, à ortografia e à elaboração de resumos. Nas fanfics, pode-se observar a união de esforços de diferentes pessoas para escrever os textos, 
disseminá-los, gerenciar/responder os comentários do público. O dialogismo se manifesta notoriamente.

O comportamento e o discurso de Emily também revelam que gosta de literatura, tanto pela admiração pela arte feita com as palavras, quanto pela reflexão sobre os próprios sentimentos. Enfoca, em acréscimo, o caráter estético, ligado às emoções, que se dá por meio dos enunciados. Ela se mostra engajada em transmitir o interesse pela literatura aos alunos.

Antes de serem analisadas as falas de Dante, faz-se necessário expor o conceito pessoal que ele aborda sobre literatura, até porque ele só conseguiu dar continuidade à entrevista, depois de esclarecer o seu posicionamento.

[...] as aulas de português no ensino médio do estágio... A gente estava dando aula, ah, sobre o que é literatura e se literatura é só os livros ou tudo o mais, então a gente deixou bem amplo esse lance de literatura. Literatura não é só livros. Às vezes é mais, tipo, você tá vendo um filme, ele pode ser literatura, pois antes ele também foi um script. Literatura também pode ser um mangá e jogo e tal, porque tem toda a história e toda a confabulação por trás disso tudo. Então você pode tirar muito de um jogo, tanto quanto você pode tirar de um livro. [...] Às vezes um pode dar mais que o outro.

Cassany (2010) elenca algumas diferenças significativas entre as formas de leitura tradicional (escrita no papel) e na internet: o formato eletrônico propicia maior facilidade de acesso e distribuição de textos, multimodalidade, plurilinguismo, diversidade dialetal, e interação e escrita ideofonemática. Por meio da rede, há maior extensão de acesso, permitindo que se compartilhe textos com amigos próximos e distantes.

A multimodalidade expressa a integração de elementos não-verbais. O plurilinguismo e diversidade dialetal exprimem o uso de vários idiomas de maneira harmônica e espotânea. A prática literária desenvolve, nestes jovens, tanto aspectos de leitura e escrita de seus textos, quanto dos comentários escritos entre os pares. Algumas das práticas de leitura escolarizadas parecem desconexas e desconectadas de seu mundo e de sua identidade, ao passo que na internet, se privilegia a interação significativa.

Sendo assim, ressalta-se que a internet possibilita a integração de diversidade de gêneros, promovendo uma primorosa riqueza linguística. Por conseguinte, não se trata de demonstrações pobres ou caóticas que devem ser rejeitadas ou marginalizadas pela escola e outras instituições que elegem práticas de leitura e escrita dominantes (STREET, 2014). O que compreende, no entanto, que essas práticas socialmente situadas, são o resultado das ações e dos discursos que constituem leitores meninos e meninas, jovens espontâneos, os quais trazem a sua leitura de mundo, o seu conhecimento prévio, seus interesses e as suas competências linguísticas, literárias e suas habilidades com computadores para instituições que elegem outras práticas de leitura e escrita e marginalizam/não validam as práticas situadas no contexto fora da escola/da universidade. 
As instituições que representam a lei e que acabam por reforçar esse discurso dominante de práticas de letramento dominantes (escola, biblioteca, publicação) devem prestar atenção a esta área tradicionalmente negligenciada. Por exemplo, a fala de Dante aponta que poderiam existir elos entre práticas dominantes e vernaculares:

Eu sempre gostei de ler. Eu sempre comecei com livros. [...] cresci rodeado de livros infantis. [...] De literatura infanto juvenil eu fui pros mangás. Aí eu comecei a ler tanto mangá mas tanto mangá e eu comecei a ler em português e daqui há pouco comecei a ler em inglês.

Dante se refere ao início da formação de sua identidade leitora. A identidade leitora abarca três estruturas: cognitiva, emocional e social. É um processo que cada sujeito desenvolve por meio da interação com a cultura letrada da sua comunidade, desde o nascimento. Esta identidade está atrelada às convenções sociais sobre conteúdos que devem ser lidos, bem como seus modos de leitura e objetivos. Sendo assim, a identidade leitora vai sendo formada pela soma de eventos de letramentos que cada pessoa vai acumulando durante a vida, e aos sentimentos que eles despertam. Também é perpassado pelas crenças e valores (ALIAGAS; CASTELLÀ; CASSANY, 2009). Para Dante, sua identidade leitora iniciou com diversos livros, e foi recebendo, posteriormente, influências de outros suportes de texto, como, os digitais. Dante destacou que atualmente a rede social mais utilizada por ele para fins relativos à literatura é o YouTube, e justificou essa relação:

É o que eu tava discutindo com o meu parceiro de estágio né, com meus alunos e tudo mais, então, o ser humano precisa sonhar para manter a mente dele sã. Assim como a nossa personalidade precisa confabular, divagar, pensar em histórias, a gente precisa de fantasia na nossa vida pra conseguir se manter de pé de vez em quando. [...] Então, por exemplo, você pode adquirir bastante da literatura através de vídeos do YouTube, como já falei nessa entrevista inteira, né?

Esses dizeres de Dante reforçam afirmar que práticas vernaculares consistem no que se lê e escreve na vida privada e ociosa, sem prescrições muito institucionalizadas como em práticas de letramentos dominantes. Estão ligadas aos interesses culturais (CASSANY; HERNÁNDEZ, 2012). Por outro lado, no contexto acadêmico, geralmente, se prestigia apenas a leitura de textos que representam o cânone, negligenciando, assim, textos que não sejam classificados como científicos ou literários. Vários jovens concluem o período da escolaridade, sem participarem de práticas de leitura com esses textos. Parte desses leitores lê no contexto privado, textos produzidos por seus colegas, ou outras produções que fogem das legitimadas pelas instituições educacionais, mas, são materiais prenhes de significado e sentido para os jovens, que são motivadores porque eles estão ligados à sua vida, afinal, encontram nelas os meios para confabular, divagar, fantasiar.

Muitas vezes as resistências que os jovens manifestam diante da leitura/escrita institucionalizadas, não se pautam em dificuldades cognitivas de compreensão dos textos, mas em uma forma de resistência constituída por conflitos de identidade (ALIAGAS; CASTELLÀ; CASSANY, 2009). Isto é, há jovens que resistem às práticas dominantes ao constatarem que suas próprias práticas não são consideradas válidas na universidade e que buscam legitimidade de suas próprias formas de leitura e escrita. O discurso de Dante, 
voltado à promoção da utilização de recursos digitais voltados à literatura pode ser uma forma de expressar sua resistência à leitura exclusiva de livros.

Só que os jogos te colocam num universo inteiro dos livros, dos personagens e você tem muito mais interação com a história com o universo e tudo o mais. [...] Mas talvez você se interesse mais pelos jogos porque você não está só presenciando a história, mas você está vivendo ela. Também têm certos tipos diferentes de literatura, tipo, algumas visualnovels que é um tipo de jogo que é um livro, só que ele não é só um livro, ele é um livro que você interage com ele. Tipo você vê os personagens e faz o que acha que você tem que fazer. Aí têm diferentes finais. Diferentes escolhas. [...] Por isso que literatura tem vários jeitos de se ver. Tem em mangá e animê, mas o melhor tipo é mesmo naquele tipo de jogo, que é uma visual novels. [...] Eu aprecio muito a literatura através de outros jeitos, além do convencional, que seria o livro, né?

As práticas de letramentos vernaculares são vinculadas com práticas sociais significativas na vida do sujeito. Leitura e escrita estão ligadas à identidade integral do sujeito e o contexto no qual ele se insere. Há uma interação genuína. Propiciam várias estratégias pessoais e diversas resoluções. Estão relacionadas à construção de sentido dos sujeitos envolvidos. Além do mais, a internet tem permitido aprimorar tais práticas, possibilitando compartilhá-las com um número maior de pessoas, inovando também as estruturas de escrita e apresentação, além de propiciar a ampliação da experiência e do repertório linguística(o) dos usuários (CASSANY, 2015).

Outra forma de resistência é priorizar as próprias práticas de letramentos, mas demonstrar que se está inserindo nas práticas dominantes. Para passar a impressão de que estava se tornando um leitor canônico, o jovem do estudo de Aliagas, Castellà e Cassany (2009) começou a frequentar a biblioteca, utilizou resumos disponíveis na internet, emulando ter lido os textos na íntegra, se aproximou dos alunos com melhores rendimentos escolares da sala, fingiu estar lendo, criou histórias e afirmava tê-las lido em algum livro (ALIAGAS; CASTELLÀ; CASSANY, 2009). Dante também fez questão de abrir sua mochila antes da entrevista iniciar e mostrar quantos livros estava levando dentro dela. Por ser acadêmico do curso de Letras, certamente ele precisou efetivar de fato muitas leituras em livros.

Certamente Dante pensou que ao mostrar os livros que levava consigo, comprovariam que ele é um leitor. Ele gerenciou a impressão que transmitiria à pesquisadora ao mostrar os livros. Este comportamento está atrelado à formação de identidade, e possivelmente também serve para que ele próprio se sinta letrado.

Eu lembro que tinha algum personagem de fanfic que ele acabou entrando na literatura principal... [...] Então, às vezes a fanfic pode entrar no canônico. [...] Tem bloguers, que são dedicados exclusivamente pra fanfic.

Assim, o discurso de Dante também deu mostras de que a linha divisória entre práticas vernaculares e legitimadas não é tão cristalizada. Por vezes, o vernacular retroalimenta práticas institucionalizadas e vice e versa. 
Aí você passa esse seu sonho, que pode tornar-se objetivo, pra literatura, pra qualquer meio, através de fanfic, através de livro, filme, você conta essa história pra alguém, você pode conhecer alguma pessoa através disso, sabe... Então... através dos meios digitais ela vai ajudar a espalhar muito isso pra todo mundo assim. Tipo, antes você tava limitado só a pessoas ao seu redor né, só que hoje em dia se você tem um tambler, e vários seguidores, você pode criar uma história que vai ficar super famosa e talvez algum dia possa até ser reconhecida pelos criadores né. [...]

Na internet os jovens têm as audiências autênticas, criando reais situações de comunicação, onde a leitura e a escrita visam a busca de significados e a produção de sentidos; a interação com esses públicos tem componentes pessoais e emocionais, de modo que a leitura e a escrita são relacionados com a construção da identidade social e acabam sendo uma ferramenta para estabelecer vínculos emocionais mais fortes (CASSANY; HERNÁNDEZ, 2012). Dante enuncia ainda:

Só que eu nunca entrei num grupo de scanlation porque, porque, porque, o que eu faria é traduzir pro português do inglês e não do japonês. Depois me toquei eu não taria realmente traduzindo a história. Eu estaria apenas traduzindo uma tradução, né? Então o que eu queria mesmo era traduzir direto do japonês. Então foi mais uma coisa que me incentivou a ir atrás do japonês. Até pra que eu quem sabe começar o meu próprio grupo de scanlation, ou entrar num grupo de scanlation, pra começar a ler os mangás em japonês scannear e fazer a tradução logo de cara, assim.

Os sujeitos inseridos em grupos de scanlation tomam inúmeras medidas na hora de fazer a tradução, procurando frases equivalentes entre o japonês e o espanhol, evitando assim, a utilização do inglês como idioma intermediário. Estes também procuram elaborar versões pautadas em questões culturais, fugindo de traduções literais, que no outro idioma podem perder o sentido (PORRAS; CASSANY, 2016). O que se pode depreender ainda na voz de Dante é o pertencimento a um grupo do qual as práticas de leitura direcionadas para uma literatura original/autêntica escrita em japonês implique na identidade desse leitor. Apesar de não dominar o idioma japonês, as leituras de Dante estão pautadas nesse idioma porque já fazia a leitura de mangás. A tradução desses textos exigem domínio do código escrito, ampliação do repertório linguístico, conhecimento cultural, social em que a produção desse tipo de literatura é produzido e veiculado, neste caso, na e pela internet. Conforme ressalta Dante:

Então eu faria parte de um grupo de scanlation hoje em dia, só pelo fato do divertimento. Mas eu também posso me profissionalizar nisso e fazer tradução direta de mangás e ser contratado por uma editora que traz mangás direto do Japão pro Brasil, daí pronto, ao invés de fazer parte de um grupo de scanlation, eu faço parte de um grupo de tradução oficial assim.

O que enuncia Dante vai ao encontro da pesquisa que Zhang e Cassany (2016) fizeram acerca da organização, funções e regras em escrita colaborativa, numa comunidade de fansub, que legendava vídeos originalmente em idioma espanhol para o chinês. Para tanto, analisaram uma comunidade digital de fansubbers amadores, que voluntariamente desenvolvem esta tarefa complexa, multimodal e multilíngue, cujo canal já ultrapassa dez 
mil inscritos. Trata-se de uma pesquisa de cunho qualitativo, fazendo uso de técnicas da netnografia. Dentre os resultados obtidos, destaca-se a cooperação entre os membros da comunidade, a descrição do desencadeamento do trabalho virtual envolvido, como por exemplo, a estrutura hierárquica, e a utilização de diferentes canais virtuais que têm revolucionado as formas tradicionais de leitura (ZHANG; CASSANY, 2016) e se assemelha ao interesse de Dante quando afirma querer fazer parte desse grupo de tradução oficial do idioma japonês.

Entende-se, deste modo, que os membros da comunidade digital são motivados pelo seu interesse em idiomas, na cultura e no compromisso com a comunidade, considerando que na China, há restrição ao acesso de produtos culturais estrangeiros. Vale ainda mencionar o aspecto identitário desta atividade, pois, desta forma, os membros podem criar, recriar e reivindicar sua própria identidade digital. Há vários papéis e funções que são distribuídos entre os membros, como, por exemplo: líder, transcritor, revisor, temporizador, editor, tipógrafo, codificador, executivo responsável etc. Eles também se organizam para realizarem o recrutamento de novos membros e a avaliação de desempenho. Além disso, fansubbers chineses elaboraram um código de ética, a fim de evitar conflitos tanto com empresas comerciais quanto com outras comunidades de fasubbers. Embora os membros não sejam recompensados monetariamente, eles são beneficiados com acessos especiais a determinados recursos audiovisuais, e às participações especiais nos fóruns (ZHANG; CASSANY, 2016). O que implica dizer, que Dante tenha esse interesse pelos benefícios que pode vir a ter, ou seja, um acesso mais fácil e rápido as obras escritas no idioma japonês.

Os resultados ainda apontam para o eficiente processo de organização do trabalho, com destaque para a notável produtividade, e autonomia dos participantes. Observa-se que as tecnologias digitais têm contribuído para que os limites geográficos e temporais sejam superados. A era digital tem permitindo que fãs que estão espalhados em locais diversos possam unir esforços na propagação dos produtos de seus ídolos, conhecendo novas pessoas, construindo o sentimento de pertencimento de um grupo (ZHANG; CASSANY, 2016). O que reverbera no que enuncia Dante, uma vez que vai buscar na internet as leituras em japonês que não consegue encontrar muitas vezes no papel com a agilidade, rapidez e com o diálogo que pode ter/fazer com outros leitores pertencentes a esse grupo de leitura japonesa (mangás). A interação e mediação que a internet acaba possibilitando a esses sujeitos a partir de um interesse comum, vislumbra uma linguagem que é social, histórica e inacabada, assim como são esses sujeitos-leitores de mangás.

Ainda, destaca-se o trabalho de Porras e Cassany (2016) sobre uma comunidade hispânica de scanlation de mangás (digitalização, tradução, edição e disseminação) por equipes transnacionais de fãs. A comunidade também se organiza dividindo o trabalho em funções interdependentes, comunicando-se por meio de espaços virtuais. As atividades 
abrangem grande complexidade, já que envolvem diversificados recursos semióticos e vários idiomas. Parte considerável dos participantes da comunidade, elege para si, um pseudônimo atrelado aos mangás - o que reforça a questão identitária.

Os scanlators consideram-se piratas editoriais sem fins lucrativos. Eles pretendem apoiar as indústrias de mangá, evitando conflitos legais. Acreditam que o trabalho desenvolvido por eles é uma medida paliativa na intermediação cultural, nas indústrias oficiais de mangás. Contentam-se com o reconhecimento obtido por meio destas atividades, ao terem seus pseudônimos presentes na parte que exibe os créditos pelas edições e traduções. Ainda faz parte da ética entre eles, não se apropriar de projetos que já estejam sendo desenvolvidos por outros grupos, afinal, reconhecem o trabalho dos demais, na seção dos créditos (PORRAS; CASSANY, 2016).

A forma como Dante enxerga a literatura é perpassada por vários vieses: envolvendo a linha do tempo, inclusive o que ainda está porvir. Também destacou que se trata de uma forma de transmissão da cultura. Além do lazer, e de aprendizado - que poderia ser categorizado como conhecimento, ele acrescenta o sentido de comunicação. Assim, a literatura não proporcionaria apenas um instante de lazer, mas também, comunica ideias específicas na relação e na mediação com o outro.

Na concepção de Cassany e Hernandez (2012), pesquisas como estas, podem nortear o trabalho docente com acadêmicos que se dedicam mais em suas práticas de letramentos vernaculares, do que nas instigadas pela universidade. Ao saber o que os acadêmicos fazem fora da sala de aula, pode-se fazer um pequeno apanhado sobre as práticas que os jovens realizam com a leitura e a escrita. Pode-se também, perguntar aos acadêmicos o que eles estão lendo e escrevendo, e discutir sobre isso com eles. Solicitar que tragam exemplares dos seus textos para a sala de aula, instigando-os a problematizar semelhanças e diferenças entre estes textos e os que circulam no contexto acadêmico. Ainda, estimular que justifiquem tais distinções.

Cassany e Hernández (2012) acrescentam que nas atividades que envolvem leitura, em vez de pedir por escrito e individualmente pelo o que é valorizado em termos canônicos, (o que costuma ser determinado pela universidade), pode-se solicitar que formem pares ou trios de estudantes para trocararem interpretações pessoais e espontâneas, oralmente, a partir de propostas como: "O que este texto significa para mim aqui e agora?" Em trabalhos escritos, pode-se buscar contextos autênticos de comunicação (fóruns, leitura em pares) e de cooperação (wiki, atividades em grupo), onde a leitura e a escrita sejam também um instrumento de troca e de construção do conhecimento (CASSANY; HERNÁNDEZ, 2012).

Quando qualquer assunto for tratado, podem ser incorporadas várias fontes (de papel e da internet) e também de vários campos (opiniões pessoais, dados científicos, enciclopédias, livros didáticos), que os alunos podem utilizar para comparar e analisar em pequenos grupos. O intuito é buscar recuperar acadêmicos, como esta jovem do estudo de 
caso, para o contexto da universidade, incentivando que os jovens sejam propriamente leitores e escritores tanto dentro, quanto fora da escola/da universidade (CASSANY; HERNÁNDEZ, 2012).

Há professores que são resistentes aos usos das tecnologias de informação e comunicação. Porém, Cassany (2016) defende que conhecer as redes que os acadêmicos utilizam é proveitoso, por se tratar de práticas cotidianas realizadas por eles, e muitas vezes, eles as empregam para fins de aprendizagem, por meio da interação com os colegas de sala, ou com outros pares. Cassany (2016) ainda recomenda que professores utilizem as mesmas redes que seus acadêmicos, para interagirem com eles por meio delas, para promover reflexões referentes aos conteúdos, tirar dúvidas e animar/motivar os estudantes. Além disso, os professores também podem beneficiar-se pessoalmente das redes sociais, para seguir os autores prediletos, integrar grupos, contribuindo para a formação continuada, e manter-se informado das novidades da sua área de atuação, de maneira rápida e multimodal.

Como foi visto, a internet tem possibilitado a multiplicação e disseminação de diversificadas formas de ler e escrever. Assim, novos sentidos vêm sendo construídos acerca da leitura e da escrita. Além disso, muitas comunidades de fãs têm empregado os ambientes virtuais para superar barreiras de linguagem, espaço e tempo, para unir esforços em ações cooperativas e voluntárias (PORRAS; CASSANY, 2016) na e pela relação com o outro.

\section{Conclusão: vários “jeitos” de se apreciar literatura na internet}

O presente estudo, que buscou compreender as práticas de letramento vernaculares com literatura desenvolvidas por acadêmicos do curso de Letras em ambientes virtuais, permitiu um olhar exógeno para práticas de leitura e escrita institucionalizadas como é o caso da escola e da universidade. Os discursos dos três acadêmicos de um curso de Letras, sinalizou para práticas situadas de literatura quanto ao uso de novos suportes para a realização dessas leituras, na internet.

A partir disso, depreende-se que se por um lado, esses estudantes têm apontado para práticas de literatura direcionadas para o meio digital por se identificarem e se constituírem leitores na e pela interação e mediação naquele contexto em dado tempo e espaço; por outro lado, o que se pode considerar é que ainda, em contextos institucionalizados, como é o caso, da universidade, essas práticas sociais não têm sido legitimadas, validadas, aceitas como sendo pertencentes ao letramento acadêmico, dominante e/ou ainda autônomo (BARTON; HAMILTON, 2000).

Esses dados refletem e refratam os enunciados dos sujeitos dessa pesquisa,acerca de uma leitura ainda pautada nos padrões aceitos/legitimados pelo professor, o qual é 
atravessado, em muitos momentos, por discursos dominantes, homogeneizantes que também o constituem e o interpelam naquele contexto de interação, de ensino e aprendizagens.

Há que se atentar, contudo, que o ser humano, na perspectiva assumida aqui nesse trabalho é aquele que se constitui na e pela linguagem na interação verbal com o outro. É nessa relação, pontualmente, aqui nessa investigação assinalada pelos sujeitos a partir das suas práticas de literatura situadas na internet.

Há diversos indícios de que o conhecimento de mundo, e outras práticas de letramento que o estudante traz/apresenta na sala de aula, especialmente, em um curso de Letras, podem permitir outras leituras. A aprendizagem se efetiva por meio da relação com o outro e consigo mesmo, e que a partir dessa mediação e troca, amplia o repertório linguístico e o repertório das experiências de mundo, aliando as práticas sociais de leitura de literatura, que traz para esse lugar social, a universidade neste caso, e a articula, dialoga com/sobre essa prática e de outras identidades que constituem aquele espaço.

\section{Referências}

ALIAGAS, Cristina L.; CASTELLÀ, JosepM.; CASSANY, Daniel. Aunqueleapoco, yo sé que soylisto. Estudio de caso sobre un adolescente que no lee literatura. OCNOS, Cuenca, 5, p. 97-112, 2009.

BAKHTIN, Mikail M. Marxismo e filosofia da linguagem: problemas fundamentais do método sociológico na ciência da linguagem. 11. ed. São Paulo: Hucitec, 2004.

BARTON, David; HAMILTON, Mary.Local literacies: Reading and writing in one community. London and New York: Routledge, 2000.

BOGDAN, Roberto; BIKLEN, SariKnoop. Investigação qualitativa em educação.Uma introdução à teoria e aos métodos. Portugal: Porto, 1994.

CASSANY, Daniel. Leer y escribir literatura almargen de laley. In. CILELIJ [I CongresoIberoamericano de Lengua y Literatura Infantil y Juvenil]. Actas y Memoria delCongreso. Madrid: Fundación SM, Ministerio de Cultura de España, 2010. p. 497-514.

CASSANY, Daniel. Las ortografia sen Internet: exploración, datosy

Reflexiones. In: Montoro del Arco,Esteban T. (Ed). Estudios sobre ortografia delespañol, Lugo: Axax. p. 13-26, 2015.

CASSANY, Daniel. Redes sociales para leer y escribir. In: FAZ, Gerardo Bañales; BADÍA, Montserrat Castelló; LÓPEZ, Norma Alicia Veja. (Org.). Enseñar a leer y escribir em laeducación superior:propuestas educativas basadasenlainvestigación. México: Fundación SM, 2016. p. 187-208.

CASSANY, Daniel; HERNÁNDEZ, Denise. “¿Internet: 1; Escuela: 0?”. CPU-e, Revista de Investigación Educativa, v.14, enero-junio 2012. Disponível em: http://www.uv.mx/cpue/num14/opinion/cassany_hernandez_internet_1_escuela_0.html. Acesso em: 20 set. 2019.

GASKELL, George. Entrevistas individuais e grupais. In: BAUER, Martin. GASKELL, George. Pesquisa qualitativa com texto, imagem e som: um manual prático. Petrópolis: Vozes, 2002. p. 64-89.

FRITZEN, Maristela Pereira. Desafios para a educação em contexto bilíngue (alemão/português) de língua minoritária. Educação Unisinos,16(2):161-168, maio/agosto 
2012.

http://revistas.unisinos.br/index.php/educacao/article/view/edu.2012.162.08/971. Acesso em: 20 set. 2019.

PORRAS, Maria J. Valero; CASSANY, Daniel. "Traducción por fans para fans": organización y prácticasen uma comunidad hispana de scanlation. Textos Universitaris de Biblioteconomia i Documentació, 37, diciembre, 2016. 12. p.

STREET, Bryan. Abordagens alternativas ao letramento e desenvolvimento. TELECONFERENCIA UNESCO BRASIL SOBRE LETRAMENTO E DIVERSIDADE, out. 2003. Paper entregue após o evento.

STREET, Bryan. Letramentos sociais: abordagens críticas do letramento no desenvolvimento, na etnografia e na educação. São Paulo: Parábola, 2014.

STREET, Bryan. Políticas e práticas de letramento na Inglaterra: uma perspectiva de letramentos sociais como base para uma comparação com o Brasil. Cad. CEDES, Campinas, v. 33, n. 89, p. 51-71, abr. 2013. Disponível em: http://www.scielo.br/scielo.php?script=sci_arttext\&pid=S0101-

32622013000100004\&lng=pt\&nrm=iso. Acesso em: 17 set. 2019.

ZHANG, Leticia Tian; CASSANY, Daniel. Fansubbingdelespañol al chino: organización, roles y normas em la escritura colaborativa. Textos Universitaris de Biblioteconomia i Documentació, 37, diciembre, 2016.

Recebido em: 09/08/2019

Aprovado em: 07/04/2020 